\title{
EU-US cooperation talks may hinge on access to research programmes
}

Washington. The European Union (EU) and the United States have promised to negotiate a comprehensive science and technology cooperation agreement by 1997 . But so far there is little agreement on what it should contain.

The promise was made as part of a 'New Transatlantic Agenda' endorsed at a summit meeting in Madrid on 3 December by Bill Clinton, the US president, Jacques Santer, president of the European Commission (EC), and Felipe Gonzalez, the Spanish prime minister, who headed the EU's Council of Ministers during Spain's presidency of the EU, from July to December 1995.

A statement issued after the summit said that the three participants "will negotiate a new comprehensive EC-US science and technology cooperation agreement by 1997 based on the principle of mutual interest, with a view to achieving a balance of benefits to us both".

Negotiations are expected to be tough as the United States and the EU have different expectations from an agreement. Officials at the commission would like European researchers to have better access to federally supported research programmes in the United States. Their US counterparts, on the other hand, want a narrower 'umbrella' agreement, primarily concerned with bringing patenting arrangements into line.

Concern about such 'institutional mismatching' between cooperating partners led to the rejection by the EU of a collaboration proposal offered by the United States 18 months ago. According to Jose Costa, science counsellor for the EC in Washington, this proposal was "an empty shell, which only allowed for consultation and for intellectual property rights".

Costa says that such an agreement would suit the United States, as it would leave the decentralized network of US research agencies to make their own deals with the Europeans. But the Europeans fear that this would allow the United States to gain access to Europe-wide research programmes while comparable US programmes funded by, for example, the Department of Energy, could remain closed at that agency's discretion.

"There is no systematic approach to this in the United States," says Costa. "You have everything from very open doors at the National Institutes of Health to others that are far more restrictive."

In March 1994, representatives of the EC and the European Parliament met in Brussels (see Nature 368, 385; 1994) to discuss a report - commissioned by the parliament's
Office of Scientific and Technological Operations Assessment - on technological cooperation with the United States and Japan.

Anne-Marie Goedmakers, a Dutch member of the European Parliament, said that it was unfair that European subsidiaries of US and Japanese companies could take part in EU research programmes, when subsidiaries of European companies were excluded from some US national programmes. The United States has already started to win access to some EC research programmes, such as the next phase of Esprit, the commission's information technology programme. US science agencies hope that any agreement will help to accelerate this process.

Jean Hudson, of the international programmes division of the National Science Foundation (NSF), says that she is enthusiastic about the prospect of any agreement that would improve transatlantic cooperation. "The United States is a large and wealthy country, and there are a lot of resources here, so US scientists are less likely than others to travel [abroad]. There have been huge strides in European countries' [scientific] capabilities, and we are not doing our job if we don't facilitate access there for our researchers."

Nevertheless, Hudson says, other factors are drawing scientists from the two regions apart. "On both sides, we feel that transatlantic ties are weakening," she says. "US scientists face a difficult job market, so they travel less. And European programmes encourage European scientists to stay in Europe."

Hudson adds that US scientists are excluded from some European-level biotechnology and materials research programmes to which she would like them to have access. But the official US approach, led by the State Department, has been minimalist, merely proposing an agreement that would set rules for patenting, and leaving agencies such as the NSF to win access to European programmes later on.

"The access issue should be separated from this agreement," says Cathy Campbell at the White House's Office of Science and Technology Policy. "The agreement is to provide a framework for agencies to develop agreements with their counterparts in the European Union."

Officials on both sides say that the United States does not want to include the question of access in the talks, as its negotiators are ill-placed to deliver the cooperation of its diverse spectrum of research agencies. "We cannot change US law," says Campbell bluntly. "We have explained that to the European Union."

Officials at the European Commission must now draw up counter-proposals in order to win a mandate from the Council of Ministers to begin negotiations whose outcome is hard to predict. Despite the language of the communiqué, the officials say that the two sides are not committed to reach an agreement by 1997 , but only to try to do so.

Some observers doubt the likelihood of any substantial agreement being reached. An official of one EU member country, who asked not to be named, said that the Madrid language was deliberately vague because officials had failed to agree anything more specific to put in the communiqué.

Colin Macilwain

\section{Fermi award honours his former student}

London. An 83-year-old atomic physicist, whose theories helped develop the laser, and an 82-year-old chemist who discovered the radioisotope carbon-14, have been named by US president Bill Clinton as the winners of this year's Enrico Fermi award.

Italian-born Ugo Fano, professor emeritus at the University of Chicago and one of the last living students to have worked with Enrico Fermi, will receive the award with Canadian-born Martin Kamen, professor emeritus at the University of California at San Diego.

Kamen discovered the long-lived radioisotope in 1940 in collaboration with the late Sam Ruben. Carbon-14 today is used for applications including dating archaeo- logical finds and tracking carbon dioxide in the environment. Fano's work on the interaction of radiation and matter has helped the development of nuclear medicine.

The 40-year-old award, which carries a $\$ 100,000$ honorarium and gold medal for each winner, is the US government's oldest science and technology award. It is granted in recognition for a lifetime's achievement in the field of nuclear energy.

The US president approved the winners from recommendations made by Hazel O'Leary, Secretary of Energy following an evaluation of candidates by a screening panel and an interagency awards committee. O'Leary will present the awards at a ceremony in Washington later this year. 